\title{
A atualidade da crítica de Adorno para as pesquisas qualitativas com bases empíricas em educação
}

\section{The currentness of Adorno's Criticism for qualitative research with empirical bases in education}

Pedro Savi Neto ${ }^{1}$

\begin{abstract}
Resumo: Neste artigo, serão apresentados dados e argumentos sobre a atualidade da crítica de Theodor W. Adorno para as pesquisas qualitativas com bases empíricas em educação, com especial ênfase à hermenêutica objetiva, desenvolvida por Ulrich Oevermann e aplicada por Andreas Gruschka às pesquisas em educação. $\mathrm{O}$ tema será abordado da seguinte maneira: (a) serão apontados elementos históricos e teóricos do desenvolvimento de um método de pesquisa próprio pela Teoria Crítica; (b) serão apresentados elementos caracterizadores da hermenêutica objetiva; (c) para, por fim, apresentar algumas das contribuições de Gruschka na aplicabilidade do referido método às pesquisas educacionais na Alemanha, além de algumas experiências no Brasil a partir da referida abordagem de pesquisa.
\end{abstract}

Palavras-chave: Theodor W. Adorno; Teoria Crítica; Hermenêutica Objetiva; pesquisa em educação.

Abstract: In this article, we will present data and arguments about the relevance of Theodor W. Adorno's critique for qualitative educational research with empirical bases, with special emphasis on objective hermeneutics, developed by Ulrich Oevermann and applied by Andreas Gruschka to educational research. The theme will be treated as follows: (a) historical and theoretical elements of the development of a research method by the Critical Theory will be pointed out; (b) characterizing features of objective hermeneutics will be presented; (c) to finally present some of Gruschka's contributions to the applicability of this method to educational research in Germany, as well as some experiences in Brazil from this research approach.

Keywords: Theodor W. Adorno; Critical Theory; Objective Hermeneutics; educational research.

\section{Introdução}

A hermenêutica objetiva é uma abordagem de pesquisa sociológica qualitativa, desenvolvida sobre bases empíricas, concebida por Ulrich

\footnotetext{
${ }^{1}$ Pós-doutorando, com bolsa PNPD/Capes, e Professor Colaborador do PPG em Educação da PUCRS, ligado ao Núcleo de Educação, Cultura, Ambiente e Sociedade (NEAS). < pedro.savi@pucrs.br >
} 
Oevermann no final da década de 1960, e que vem sendo amplamente utilizada na Alemanha em pesquisas no campo da educação, especialmente desde a década de 1980. O referido método de pesquisa, diretamente influenciado pela Teoria Crítica da Sociedade, combina elementos da dialética negativa de Theodor Adorno, com a tradição hermenêutica e a sociologia estruturalista.

Neste artigo, serão apresentados alguns elementos caracterizadores da referida abordagem de pesquisa, traçando um roteiro de referências possíveis para um estudo mais aprofundado do tema, dentre os quais, desde já, destacam-se as pesquisas de Rita Amélia Teixeira Vilela (2009; 2010; 2011) e de Luiz Roberto Gomes (2017), ambos pesquisadores referência em Teoria Crítica e hermenêutica objetiva no Brasil. O tema será abordado da seguinte maneira: (a) serão apontados elementos históricos e teóricos do desenvolvimento de um método de pesquisa próprio pela Teoria Crítica $^{2}$ e sua relação com pesquisas empíricas; (b) serão apresentados elementos caracterizadores da hermenêutica objetiva; (c) para, por fim, apresentar algumas das contribuições do pesquisador alemão Andreas Gruschka na aplicabilidade do referido método às pesquisas educacionais na Alemanha, além de algumas experiências no Brasil a partir da referida abordagem de pesquisa.

\section{A Teoria Crítica}

\subsection{O desenvolvimento de uma abordagem metodológica própria:}

Berço da formação e do desenvolvimento inicial da Teoria Crítica, o Institut für Sozialforschung (Instituto de Pesquisas Sociais de Frankfurt IPSF) ${ }^{3}$, sob a direção de Max Horkheimer, se afastou da tentativa de pensar

\footnotetext{
${ }^{2}$ No âmbito deste texto, o termo Teoria Crítica se refere somente aos autores da chamada primeira geração do Instituto de Pesquisas Sociais de Frankfurt, dentre os quais destaco: Max Horkheimer, Erich Fromm, Theodor Adorno, Herbert Marcuse, Friedrich Pollock, Franz Neumann, Leo Löwenthal e Otto Kirchheimer.

${ }^{3}$ Embora não seja a nossa intenção neste texto, faz-se importante tecer algumas considerações sobre a distinção entre as denominações Teoria Crítica e Escola de Frankfurt (para compreender adequadamente a questão v. FLECK, 2017; NOBRE, 2014), apenas na medida em que se faz necessário para a compreensão da hermenêutica objetiva e de quais características da Teoria Crítica a influenciaram. O termo escola é problemático, pois, embora os pesquisadores do movimento inicial tivessem a obra de Marx como referência, não havia a unidade de pensamento que caracteriza uma escola. Foi uma terminologia que surgiu apenas na década de 1950, quando Horkheimer e Adorno voltaram do exílio americano para a Alemanha. Assim, Escola de Frankfurt: "designa antes de mais nada uma forma de intervenção político-intelectual (mas não partidária) no debate público alemão do pós-guerra, tanto no âmbito acadêmico como no da esfera pública entendida mais amplamente”. (NOBRE, 2014, p. 20). Nesse sentido, é possível
} 
a aplicação da teoria marxista à realidade, enquanto socialismo ou comunismo, e se voltou para as principais questões do jovem Marx, relativas ao aspecto existencial de sua teoria, como os conceitos de alienação, ideologia e reificação ${ }^{4}$. Para o grupo, a crítica não foi mera opção teórica, mas um caminho inevitável para um conhecimento com pretensões racionais no contexto de injustiça da sociedade burguesa. Para o desenvolvimento de abordagens teórica e metodológica próprias, partiram do pressuposto que a sociedade burguesa se deixava conhecer através das contradições entre aquilo que prometia, a partir da pretensão iluminista, e aquilo que efetivamente se percebia na realidade social, como decorrência da aplicação dos interesses burgueses à sociedade.

Se, por um lado, o movimento da crítica foi direcionado contra a injustiça, entendida como inerente à sociedade burguesa, por outro, mostrava-se necessário pensar e colocar em prática uma abordagem de pesquisa dotada de mecanismos capazes de identificar e tratar teoricamente a injustiça. Nesse sentido, o método deveria ser capaz de desvelar, a partir da crítica imanente das contradições da realidade, a falsidade das promessas contidas nos ideais burgueses e aquilo que se fazia, de fato, presente na realidade social. Essa é uma característica tão fundamental desse grupo de pesquisadores que, por si só, pode ser compreendida como um dos principais traços identificadores da Teoria Crítica (FLECK, 2017, p. 108). A abordagem metodológica desenvolvida pelo grupo pode ser entendida a partir de três questões fundamentais: (a) a distinção, teorizada especialmente por Horkheimer e Adorno, entre Teoria Crítica e Teoria Tradicional5; (b) a defesa de um projeto interdisciplinar de pesquisa, como forma de proporcionar um conhecimento mais completo dos objetos de estudo (num momento

compreender a denominação Escola de Frankfurt como um momento da Teoria Crítica. Por outro lado, a denominação Teoria Crítica surgiu pela primeira vez no texto de Horkheimer, de 1937 (Teoria Tradicional e Teoria Crítica), publicado na revista do Instituto de Pesquisa Social, a Zeitschrift für Sozialforschung. Teoria Crítica designa uma abordagem teórica de um grupo específico de intelectuais filiados ao campo, inicialmente reunidos em uma instituição (FLECK, 2017; NOBRE, 2014; WIGGERSHAUS, 2002). Em que pese exista um grande trabalho de produção acadêmica que fale de diferentes gerações da Teoria Crítica, parece-nos mais adequado o posicionamento no sentido de que houve apenas uma geração de pesquisadores que manteve, embora com particularidades, suas pesquisas ancoradas nos mesmos fundamentos essenciais que fundamentam a chamada Teoria Crítica (nesse sentido, FLECK, 2017).

${ }^{4}$ Os contextos histórico e teórico da formação da Teoria Crítica podem ser encontrados em Jay, 1989, e Wiggershaus, 2002.

${ }^{5}$ Além do já referido e famoso texto de 1937 de Horkheimer, tal temática é explorada na Dialética do esclarecimento e na Dialética negativa. 
histórico em que havia um crescente distanciamento entre as ciências sociais e filosofia e entre pesquisas empíricas e pesquisas teóricas); (c) o método da dialética negativa, especialmente desenvolvido por Adorno.

Nesse contexto, a teoria adquire o papel central na Teoria Crítica não de apenas demonstrar como as coisas são (o que tenderia a apenas fortalecer os interesses dominantes), mas de estabelecer a relação entre como elas são e como elas poderiam ser à luz da possibilidade da emancipação, bloqueadas pelas condições sociais vigentes: "[a] orientação para a emancipação é o primeiro princípio fundamental da Teoria Crítica.” (NOBRE, 2014, p. 32). E o segundo dos princípios fundamentais da Teoria Crítica é que a teoria deve adquirir o papel de crítica ao conhecimento produzido sob as condições do mercado e às condições sociais reais. Isso exclui da Teoria Crítica os intelectuais que usam a teoria como mera prescrição (utópicos ou normativistas) ou como descrição neutra do mundo (positivistas) (NOBRE, 2014). Uma das ideias fundamentais nas quais foi fundada a Teoria Crítica a partir de Marx é pelo esforço analítico para a superação da dominação por meio da destruição da aparência de possibilidade de liberdade e igualdade. Contudo, enquanto no âmbito da Teoria Crítica a possibilidade de transformação é confiada apenas à teoria, em Marx, a transformação seria viabilizada pela teoria, mas realizada pela prática transformadora (NOBRE, 2014).

O fundamento interdisciplinar do projeto tinha como objetivo a análise do fenômeno social em si (objeto), pois, na realidade social, não estão desenhadas as especialidades da pesquisa científica, há, apenas, um fato a ser pensado, com toda sua complexidade. De certa forma, o projeto de crítica termina por repensar a forma de aproximação à realidade dos estudos sociológicos clássicos, quando, por exemplo, Weber, Durkheim e Marx, analisaram os fenômenos integralmente, sem que houvesse o tolhimento das investigações em função da demarcação de campos próprios de pesquisa. A interdisciplinaridade do instituto teve como principal fundamento a maior possibilidade de cercar o objeto para melhor conhecê-lo. Para tanto, o IPSF lançou mão de pesquisas empíricas as quais, entretanto, comparativamente às teorias de maior grau de especulação filosófica, ainda hoje no Brasil são pouco conhecidas e estudadas.

O papel exercido por Horkheimer, como diretor do IPSF, foi fundamental na atribuição de um caráter interdisciplinar às pesquisas realizadas do instituto. Mesmo que Adorno não tenha participado 
diretamente das definições iniciais nesse sentido, o caráter explicitamente interdisciplinar de sua obra e a inegável influência das bases empíricas analisadas para a escrita, inclusive, de suas obras mais especulativas (cf. Antunes, 2014) são provas de que seu pensamento foi diretamente influenciado pela interdisciplinaridade das pesquisas realizadas pelo IPSF. O próprio Adorno analisa as consequências de um afastamento burocrático das ciências:

[o] fato de a filosofia erigida a partir do primado do método aquietar-se junto às assim chamadas questões preliminares e por isso também se sentir, tanto quanto possível, segura enquanto ciência fundamental não faz outra coisa senão enganar quanto ao fato de as questões preliminares e a própria filosofia não possuírem mais quase nenhuma consequência para o conhecimento. As reflexões sobre o instrumento há muito tempo não tocam mais aquilo que é cientificamente conhecido, somente aquilo que é em geral cognoscível, a saber, a validade dos juízos científicos. (...) Desde que as ciências se separaram irrevogavelmente da filosofia idealista, as ciências de mais sucesso não buscaram mais uma outra legitimação senão a declaração de seu método. Em sua autointerpretação, a ciência transforma-se para si mesma em causa sui... Sobretudo as ciências humanas, por meio do ideal de positividade tomado de empréstimo, tornam-se vítimas da insignificância e da aconceptualidade em inumeráveis investigações particulares. O corte entre disciplinas particulares tais como sociologia, economia e história escamoteia o interesse do conhecimento, por baixo das trincheiras cavadas de maneira pedante e defendidas de modo ultravaloroso (ADORNO, 2009, pp. 68-70).

Com base nessa preocupação, o projeto crítico buscava produzir um discurso logicamente consistente do ponto de vista filosófico, altamente especulativo, mas que em nenhum momento se afastasse da materialidade da injustiça social que lhe servia de fundamentação. Para tanto, Adorno lançou mão do conceito de dialética negativa. A escolha pela utilização da expressão dialética negativa, por si só, é algo bastante significativo. Nesse paradoxo, então, reside o ponto nevrálgico da negatividade do pensamento em Adorno.

...pode-se dizer também que o pensamento de Adorno, bem como o de outros membros da Escola de Frankfurt, tinha na dialética sua referência metodológica principal. Mas de que dialética se trata? Exatamente na dialética negativa, a expressão dessa ousadia uma petitio principii. Isto porque, para Adorno, a única "dialética" que se poderia considerar como propriamente tal seria aquela aberta, irredutível a uma "resolução" 
superior, negativa em relação à positividade da totalidade... (SOUZA, 2004, p. 98).

Este procedimento dialético negativo tem como finalidade preservar a materialidade do objeto (o não-idêntico, para Adorno). Ao afirmar a primazia do objeto, Adorno não retira a importância do sujeito na relação de conhecimento (pois, se fizesse, cairia na mesma armadilha de Kant, ao fundamentar a sua ética em uma racionalidade pura, independente do sujeito concreto). A eliminação da necessidade do sujeito na relação de conhecimento está no centro das filosofias positivistas e cientificistas criticadas por Adorno. Então, o sujeito, reconstruído a partir do materialismo e da primazia do objeto, é concreto, individualizado e materialmente situado na realidade e na história. A crítica natural a essa concepção é que, ao colocar a possibilidade de verdade no sujeito concreto, corre-se o risco de torná-la mera contingência; contudo, o seu contrário, retirar do sujeito a possibilidade de verdade, levaria a apostar em uma verdade superior, retornando ao positivismo e ao dogmatismo. A dialética negativa é o método que está no centro da resistência exercida pela Teoria Crítica à chamada Teoria Tradicional e, igualmente, está no centro da resistência da hermenêutica objetiva às metodologias de pesquisa empírica de caráter positivista e meramente quantitativo.

\subsection{Teoria Crítica e pesquisas empíricas:}

Em função do alto grau especulativo teórico da filosofia de Adorno, da sua imagem de intelectual erudito e de sua resistência à ação política, as suas incursões no âmbito da pesquisa empírica são, em geral, pouco exploradas e, muitas vezes, mal compreendidas. Essas e outras questões fizeram com que a Teoria Crítica ainda hoje (e, com bastante força, no Brasil) seja associada apenas à pesquisa teórica, negligenciando seu poderoso potencial para pensar questões relativas às pesquisas empíricas. Para melhor compreender a relação do IPSF com a pesquisa empírica é necessário ter em conta algumas questões sobre o histórico dessa relação ${ }^{6}$.

O envolvimento da Teoria Crítica com pesquisas empíricas gera as mais diferentes reações nos especialistas sobre a temática, desde a compreensão da abordagem como parte coerente dos objetivos iniciais

${ }^{6}$ Nesse sentido, v. Antunes, 2010. 
(DUARTE, 2001) até acusações de completa incoerência com os pressupostos fundamentais do movimento ${ }^{7}$. O fato é que a Teoria Crítica esteve à frente de, pelo menos, três grandes projetos de pesquisas empíricas entre 1929 e 1950, além de outros estudos menores (ANTUNES, 2010). No entendimento de Antunes (2010), os referidos estudos, além de estarem adequados ao projeto do IPSF, mantiveram uma ligação entre si.

O primeiro grande projeto de pesquisa empírica conduzido pelo IPSF foi iniciado em 1929 e dirigido por Erich Fromm, antes mesmo da posse oficial de Horkheimer. O projeto, chamado The working class in Weimar Germany ${ }^{8}$, "objetivava obter evidências sobre a existência de conexões entre a aparência psíquica e o desenvolvimento da sociedade a partir de opiniões, estilos de vida e atitudes de trabalhadores manuais e de escritório na então República de Weimar" (ANTUNES, 2010, p. 22). Tal objetivo estava totalmente de acordo com os planos de Horkheimer para o IPSF, conforme é possível verificar em seu discurso de posse proferido em 1930: "o problema da conexão que subsiste entre a vida econômica da sociedade, o desenvolvimento psíquico dos indivíduos e as transformações que têm lugar nas esferas culturais em sentido estrito" (HORKHEIMER, 1999, p. 130).

O segundo projeto, Studien über Autorität und Familie ${ }^{9}$, dirigido e publicado por Horkheimer em 1936, "se baseava na consideração do papel central da família na mediação entre a subestrutura material e a superestrutura ideológica" (ANTUNES, 2010, p. 26). Tal projeto foi uma primeira materialização empírica dos textos teóricos de Horkheimer na medida na qual foi realizado por um equipe interdisciplinar, com especialistas de diversas áreas, relacionando a empiria diretamente com a crítica filosófica (WIGGERSHAUS, 2002), embora não tenha atingido todas as expectativas de Horkheimer em termos de método (JAY, 1989).

O terceiro projeto, e mais completo em termos metodológicos, apresentando um aperfeiçoamento dos estudos anteriores, recebeu o título de Estudos sobre o preconceito. Tratou-se de um projeto coletivo escrito por Horkheimer, Adorno e outros integrantes do IPSF, iniciado em 1941, durante o período de exílio dos pesquisadores, e teve como objetivo

\footnotetext{
${ }^{7}$ Relativizam a importância dos estudos empíricos do IPSF, segundo Antunes (2010), Rolf Wiggershaus, Martin Jay, Eva-Maria Ziege e John Abromeit.

${ }^{8}$ A classe trabalhadora na Alemanha de Weimar, em tradução nossa.

${ }^{9}$ Estudos sobre autoridade e família, em tradução nossa.
} 
"combinar pesquisas histórica, psicológica e econômica com estudos experimentais” (ADORNO; HORKHEIMER, 1985, apud ANTUNES, 2010, p. 26). O projeto apenas não foi ainda mais elaborado em termos metodológicos em função do contingenciamento de seu financiamento em função das consequências da Segunda Guerra Mundial (ANTUNES, 2010, p. 27).

Os resultados das pesquisas foram lançados em cinco volumes, a saber, Dynamics of prejudice, de Bruno Bettelheim e Morris Janowitz (1950), Rehearsal for Destruction, de Paul W. Massing (1949), Prophets of Deceit, de Leo Lowenthal e Norbert Guterman (1949), Anti-semitism and emotional disorder, de Nathan W. Ackerman e Marie Jahoda, (1950), e The authoritarian personality, de Theodor W. Adorno, Elsa Frenkel-Brunswik, Daniel J. Levinson e Nevitt Sanford (1969) ${ }^{10}$ (ANTUNES, 2010, p. 27).

$\mathrm{O}$ volume dos Estudos sobre o preconceito que conta com a participação de Adorno é considerada uma das produções mais polêmicas do filósofo, porquanto conta com refinados procedimentos de coleta de dados, análises quantitativas e uma escala de medição das características da personalidade, algo que, sem a devida contextualização, soa inimaginável para o intelectual com a produção dotada de caráter altamente especulativo. Contudo, o próprio Adorno esclareceu que "[n]a sociologia dever-se-ia analisar que problemas poderiam ser tratados empiricamente de modo adequado, e que outros não, sem prejuízo de sentido. Entretanto, estritamente a priori isso não pode ser decidido" (ADORNO, 1979, apud DUARTE, 2001, p. 45).

Assim, apesar de uma suposta resistência incondicional de Adorno às pesquisas empíricas, o filósofo via com fortes ressalvas um determinado tipo de pesquisa empírica. Em verdade, ele diferenciava as pesquisas empíricas em dois tipos distintos: aquelas que ele denominava de administrative research (pesquisa administrativa), que teriam como finalidade a aplicação direta dos resultados, sendo meramente práticas, e as investigações sociais críticas, preocupadas em proporcionar uma leitura crítica da realidade social, sem qualquer caráter propositivo, abordagem adotada por ele em seu período de exílio em solo americano (ADORNO, 1995, p. 143). Nesse sentido, a distinção que Adorno faz, indica seu

\footnotetext{
${ }^{10}$ Em português, A dinâmica do preconceito, Ensaio da destruição, Profetas do engano, Anti-semitismo e desordem emocional, A personalidade autoritária.
} 
entendimento de que um método de pesquisa deve ser algo mais do que um simples quantificar, mensurar, que pode ser facilmente colocado a serviço do mercado; deve ser, dentro da tradição do IPSF, um mecanismo de crítica, dotado de uma análise teórica consistente.

\begin{abstract}
Minha posição própria na controvérsia entre sociologia teórica e empírica, que freqüentemente - principalmente em nosso país - foi apresentada de modo totalmente falso, eu gostaria de precisar de modo curto e grosso dizendo que, para mim, as investigações empíricas, mesmo no âmbito dos fenômenos culturais, aparecem não apenas como legítimas, mas também como necessárias. Não se pode, entretanto, hipostasiá-las e considerá-las como uma chave universal. Principalmente, elas próprias devem terminar em conhecimento teórico. A teoria não é apenas um veículo, que se tornaria supérfluo logo que se dispusesse dos dados (ADORNO, 1995, p. 156).
\end{abstract}

Disso, podemos compreender que a resistência imputada a Horkheimer e, ainda mais, a Adorno não está relacionada com a pesquisa empírica em si, mas com a sua apropriação pelo mercado e a sua utilização como um procedimento que se justifica por si só, sem a devida reflexão teórica crítica sobre os dados: o "objetivo também dos métodos quantitativos sociológicos seria uma visada qualitativa: quantificação não é fim em si mesmo, mas meio para isso" (ADORNO, 1979, apud DUARTE, 2001, p. 44).

Além dos três projetos acima mencionados, que foram escolhidos por serem considerados os três mais representativos do modelo interdisciplinar concebido e executado pela Teoria Crítica (ANTUNES, 2014), há projetos menores, conduzidos individualmente por Adorno e Horkheimer, em conjunto ou separadamente, além de conexões entre as bases empíricas produzidas nos diversos projetos empíricos e as obras meramente teóricas publicadas, que comprovam uma considerável conexão entre o referido movimento teórico e as pesquisas empíricas. Nesse sentido, as críticas dirigidas a Adorno e Horkheimer de teoricismo não encontram amparo em uma análise consistente das obras dos autores e do verdadeiro projeto de Teoria Crítica (DUARTE, 2001), do qual não fazem parte os autores das chamadas gerações posteriores.

Por fim, uma análise mais completa do tema, incompatível com as pretensões do presente texto, indica que os métodos de pesquisa adotados pela Teoria Crítica, especialmente por Adorno e Horkheimer, ao longo de 
suas vidas, conjunta ou isoladamente, sofreram graves restrições em função do momento histórico no qual viveram, de guerra e de exílio, com diversos momentos de dificuldade de financiamento para as pesquisas e das poucas possibilidades que tiveram de contar com coletivos de pesquisadores.

\section{A Hermenêutica Objetiva, de Ulrich Oevermann}

A hermenêutica objetiva é uma abordagem de pesquisa sociológica qualitativa, desenvolvida sobre bases empíricas, que combina elementos da Teoria Crítica, especialmente a dialética negativa de Adorno, com a tradição hermenêutica e a sociologia estruturalista. Nessa medida, para tratar da referida abordagem, foi necessário trazer ao texto alguns elementos sobre a filosofia de Adorno e sobre a Teoria Crítica, bem como sobre a relação de ambos com pesquisas empíricas, para, finalmente, chegar-se ao método de pesquisa e objeto do presente texto.

Iniciando pela questão hermenêutica em geral, esse procedimento se refere à possibilidade de interpretação do mundo através da linguagem, especialmente representada pelos conceitos. Existem diversos métodos hermenêuticos teorizados por autores como "Schleiermacher (1768-1834), Dilthey (1833-1911), Weber (1864-1920), Mannheim (1893-1947), Heidegger (1889-1976), Gadamer (1900-2002), Habermas (1929) e Ricoeur (1913)" (WELLER, 2010, pp. 289-290).

Desses, Wilhelm Dilthey foi o primeiro dos autores da tradição hermenêutica a, em 1900, afirmar a necessidade do desenvolvimento de um método hermenêutico próprio para as ciências humanas e sociais, distinto do método das chamadas ciências naturais (ADORNO, 2001). Na Alemanha, Dilthey é considerado o fundador da perspectiva hermenêutica como um método de interpretação da realidade social. Seguindo o mesmo entendimento, em 1964, Mannheim defende a importância do desenvolvimento de um método capaz de dotar as ciências humanas de um tipo de compreensão metodologicamente orientada para realizar a transição entre o conhecimento ateórico e o conhecimento teórico (WELLER, 2010). Nesse sentido, Vilela ( 2011, p. 3) afirma que 
hermenêutica de sua condição de hermenêutica do texto e transformandoa em uma hermenêutica sociológica e de crítica cultural. $\mathrm{O}$ autor afirma que, se a linguagem é a forma do pensamento se expressar "isso significa o mesmo que afirmar que a linguagem revela o que realmente é. Disso decorre que a hermenêutica sociológica precisa reconstituir o processo que definiu o modo de ser" (Kraimer, 2000, p. 28).

Não obstante as pesquisas de Dilthey, Mannheim e da Teoria Crítica, na década de 1960, as consequências da derrota na Segunda Guerra Mundial foram sentidas das mais diversas formas na sociedade alemã. Uma dessas formas é velha conhecida dos autores que se identificam com a abordagem crítica: mais uma vez, agora capitaneada pelos norte-americanos, o positivismo procura se impor como método principal às ciências em geral. Respaldado pela sua pretensa objetividade, que dotaria os resultados de suas pesquisas de maior confiabilidade, representatividade e relevância, o movimento positivista acusava as pesquisas qualitativas de um maior grau de subjetividade na análise, o que seria eliminado mediante a utilização de métodos quantitativos (WELLER, 2010). As chamadas pesquisas de opinião tornaram-se a metodologia de pesquisa dominante, na medida em que eram capazes de produzir dados que interessavam ao mercado e aos organismos de governo. No final da década de 1960, as abordagens meramente quantitativas passaram, novamente, a ser objeto de forte contestação.

No âmbito da Universidade de Frankfurt, no final da década de 1960, o sociólogo Ulrich Oevermann, formado com influências da sociologia positivista e do estrutural-funcionalismo norte-americano, foi integrado à equipe de Habermas ${ }^{11}$, passando a dedicar-se à realização de pesquisas quantitativas (VILELA, 2009; WELLER, 2010; GOMES, 2017). Oevermann coordenou, juntamente com outros dois pesquisadores, um projeto de pesquisa empírica, originalmente meramente quantitativa, no campo educacional, iniciado em 1968, denominado Origem familiar $e$ escola, que investigava a relação entre origem familiar e desenvolvimento da aprendizagem. Contudo, não satisfeito com os resultados, pois entendia que conduziam a conclusões superficiais sobre o objeto da pesquisa, Oevermann compreendeu que era necessário investigar sobre o meio

\footnotetext{
${ }^{11}$ A influência de Habermas poderá ser percebida no desenvolvimento posterior do método de pesquisa de Oevermann, contudo a hermenêutica do primeiro centra-se em questões epistemológicas, enquanto as interpretações do segundo tem como objeto dados empíricos (WELLER, 2010).
} 
social nos quais ocorriam os processos de socialização, discutindo, inclusive, os conceitos implicados. Para dar conta do rumo que havia imposto à pesquisa, Oevermann desenvolveu, juntamente com a sua equipe, um conjunto próprio de procedimentos para a coleta e análise dos dados, fundamentado na Teoria Crítica, especialmente na obra de Adorno, e "na teoria da linguagem de George Herbert Mead, no conceito de 'regra' (rules) de John Searle e no princípio lógico da 'abdução' de Jame Peirce" (REICHERTZ, 2004, apud WELLER, 2010).

A partir dessa pesquisa inicial, satisfeito com os resultados obtidos e com o procedimento adotado, Oevermann voltou a sua atenção ao desenvolvimento de um método de pesquisa centrado no que ele chamou de protocolo (texto escrito, a partir da gravação dos fenômenos sociais, objeto da hermenêutica), pois entendia que "o texto é a instância material para exame de cada interpretação dada à realidade social porque esta realidade não é outra senão a realidade registrada no texto e que só no texto pode ser examinada" (OEVERMANN, 1986, apud VILELA, 2011, p. 7). Na percepção de Oevermann, o protocolo teria a capacidade reconstrutiva do fato e, para que revelasse todo seu significado, deveria ser interpretado de acordo com a base filosófica da Teoria Crítica. Tal método foi aplicado e desenvolvido na década de 1970 e atingiu sua maturidade a partir da década dos anos oitenta do mesmo século.

Importante referir que no desenvolvimento inicial do método, a hermenêutica objetiva foi concebida como uma hermenêutica do objeto; como um procedimento que, pelo rigor do método, seria capaz de eliminar a subjetividade na elaboração do protocolo para chegar ao conhecimento da essência do objeto. Contudo, animado com os resultados decorrentes de uma sistematização rigorosa do método, Oevermann passou a confiar na objetividade, inclusive, do conhecimento gerado, como relação fidedigna entre o fato social estudado e a sua representação por meio do protocolo (VILELA, 2007; 2009; WELLER, 2010). A escolha do nome da abordagem de pesquisa em questão também pode ser entendida como decorrência do debate que havia na Alemanha à época, no qual os positivistas defendiam a objetividade dos métodos quantitativos em detrimento de um suposto caráter subjetivo dos métodos qualitativos. Nesse contexto, a denominação hermenêutica objetiva pode ser compreendida como uma resposta às críticas dos positivistas, que afirmavam que a hermenêutica seria um método de pesquisa que 
produziria resultados sem a necessária objetividade científica (VILELA 2009).

A intenção de Oevermann, recorrendo à filosofia adorniana, especialmente à noção de dialética negativa, foi de aprimorar as possibilidades de acesso ao objeto de pesquisa, para que ele revelasse, além de sua aparência, dados sobre a sua própria essência, "através de análises concretas, que se ajustando ao objeto estudado, levam o objeto a se expressar" (OEVERMANN, 1983, apud VILELA, 2009, p. 84). Nesse sentido, a filosofia materialista de Adorno, marcada pela preocupação fundamental com o objeto, é constituinte fundamental da hermenêutica objetiva. A intenção de Oevermann, resgatando o referencial teórico adorniano, era de captar no objeto, descrito por meio do protocolo, as contradições da sociedade burguesa. Entendia, na esteira da Teoria Crítica, que, não obstante, a realidade social representada por fatos sociais concretos, como opiniões, comportamentos etc., tendesse a ser encarada como subjetividade, ela conteria, em si, traços da objetividade social projetada sobre os sujeitos concretos. Nesse sentido,

[a]s opiniões e comportamentos dos sujeitos são também sempre algo objetivo. Revestem-se de importância com relação às tendências evolutivas da sociedade como um todo, embora não no grau suposto por um modelo sociológico que identifica, sem mais, as regras do jogo da democracia parlamentar à realidade da sociedade vigente. Por outro lado, nas reações subjetivas cintilam objetividades sociais, inclusive detalhes concretos. Do material subjetivo, é possível inferir determinantes objetivos (ADORNO, 1995, p. 146).

No contexto da Teoria Crítica, isso representa a potencialidade da pesquisa empírica desvelar, a partir dos pequenos fatos sociais que compõe o todo social, a contradição fundamental da sociedade burguesa entre aquilo que a racionalidade iluminista prometeu e o que efetivamente se sucedeu pelo desenvolvimento do capital. Para lograr êxito na complicada tarefa de evidenciar o objetivo nos pequenos fenômenos sociais, Oevermann concebeu um método bastante rigoroso, composto por um procedimento de coleta de dados, que visava à reconstrução mais fiel possível do evento social a partir do texto, composto, fundamentalmente, de cinco normas: 
Vilela (2012, p. 165-167) apresenta de forma didática, as referidas regras e os passos de desenvolvimento do Método: 1) Sequencialidade (Sequenzialität) é a primeira regra, e nessa, o texto deve ser analisado desde a primeira palavra registrada, em cada frase, do começo ao fim. 2) Independência do contexto (Kontextfreiheit: Kein Rückgriff auf Vorannahmen), a interpretação deve ater-se à situação registrada. O intérprete não deve subsumir sua análise em informações do contexto, ou seja, não deve projetar para a análise o que não pode ser confirmado no texto. 3) Literalidade(Wörtlichkeit), o que ocorreu e está registrado necessita ser entendido por meio do que é registrado, pois o próprio texto é o instrumento de validade da interpretação, e apenas o que está registrado deve ser analisado. 4) Substancialidade da informação (Extensivität), a interpretação hermenêutica objetiva é um processo em que cada intérprete procura explicar a sequência com base na sua bagagem de compreensão da situação em análise, pautada pelo seu conhecimento disciplinar. Mas, em vez de fazer conjecturas, os pesquisadores devem formular hipóteses explicativas, que se sucedem e permitem que a mais plausível se estabeleça. 5) Parcimônia (Sparsamkeit), de um lado, reitera a condição estabelecida nas regras anteriores: evitar conjecturas sobre o que está informado no registro, renúncia ao fictício, a considerações improváveis. De outro, indica que o processo de análise é metódico, paciente, profundo e que nãopode ser precipitado (VILELA, 2012, apud, GOMES, 2017, pp 355, 356).

Além das referidas regras, seria necessário que as análises fossem acompanhadas de um especialista no tema da pesquisa e de uma equipe de pesquisadores, que, no entendimento de Oevermann, dariam conta de eliminar a possibilidade de interpretações subjetivas. Além disso, a análise deveria ser realizada levando-se em consideração a reconstrução estrutural da experiência social objeto da pesquisa, não se atendo a fatos pontuais, preocupações que evidenciam a herança estruturalista do sociólogo. Nesse sentido, a influência estruturalista na abordagem de Oevermann se deixa notar na premissa de que tudo o que acontece na realidade social é determinado por uma lógica social, fazendo parte de uma estrutura social, na qual os acidentes casuais são percebidos enquanto meros acidentes, sem relevância (VILELA, 2007; 2009).

Atualmente, a hermenêutica objetiva é uma das mais aplicadas e valorizadas "abordagens de pesquisa das situações que envolvem as relações sociais, sobretudo, no âmbito da família, da escola e da mídia (WERNET, 2006; KRAIMER, 2000; VILELA, 2010)" (VILELA, 2011, p. 2). 


\section{Aplicação da Hermenêutica Objetiva nas pesquisas em Educação de Andreas Gruschka}

A partir de meados de 1970, a educação escolar alemã enfrentou uma abrangente crise, que culminou anos mais tarde, a partir da década de 90 do mesmo século, com fracos resultados da nação germânica em avaliações internacionais (mesmo que a importância de tais avaliações seja relativizável, o fato é que feriu o orgulho do país e desencadeou um movimento reformista). As iniciativas de reforma do modelo escolar alemão, de cunho progressista, fundamentavam-se, muitas das vezes, em pesquisas empíricas quantitativas que tinham como finalidade imediata alimentar novas políticas sociais. Além disso, tratava-se de um movimento com caráter de resposta às teorias críticas da educação que viam com pessimismo a relação cada vez mais próxima entre escola e capitalismo (VILELA, 2009).

Muitos dos escritos considerados pelos reformistas como pessimistas estavam baseados nos textos adornianos sobre educação. Contudo, de acordo com Gruschka, tais intervenções filosóficas não faziam justiça ao pensamento de Adorno, na medida em que, muitas das vezes, tomavam a filosofia adorniana como uma teoria propositiva de soluções para a longa crise da educação na Alemanha. Confusão favorecida pelo lançamento póstumo da obra Erziehung zur Mündigkeit (Educação para a autonomia, traduzido como Educação e emancipação ${ }^{12}$ ), que foi organizada por um amigo de Adorno. Desacomodado, tanto com a longa crise do sistema educacional alemão quanto com o tratamento destinado à obra de Adorno, Gruschka, que já realizava pesquisas em educação, ao menos, desde 1977, viu na hermenêutica objetiva de Oevermann uma possibilidade de resistência crítica aos referidos movimentos, que, ao mesmo tempo, se mostrava fiel ao pensamento crítico adorniano (VILELA, 2009).

\footnotetext{
${ }^{12}$ Com relação à escolha da palavra emancipação, VILELA (2007, pp. 235-236) esclarece que "Para entender o Theodor Adorno desse conjunto de textos, parece-nos fundamental esclarecer o termo alemão, utilizado por ele, para indicar o pensamento sobre a escola e a Educação, pois o vocábulo português 'emancipação' não revela o sentido pleno tomado pelo teórico. Ao escolher a palavra, Adorno procurou, com ela, revelar a essência do seu pensamento: a educação e o processo social de dominação apresentam uma mesma raiz. Mund significa 'boca'. Mündigkeit significa a capacidade de falar pela própria boca, falar por si mesmo; mas, para essa condição, o sujeito precisa ser capaz de pensar por si mesmo. Entretanto, o processo social de dominação retirou do homem a capacidade de pensar por conta própria, retirou dele a capacidade de autonomia das suas ações, de falar e de agir por si mesmo".
} 
Gruschka ingressou no Departamento de Pedagogia da Universidade de Frankfurt em 2000, integrando a equipe de pesquisas empíricas em educação que contou, desde o início, com a participação do próprio Oevermann (VILELA, 2009). As pesquisas conduzidas por Gruschka foram na direção contrária das investigações que pretendiam apresentar propostas resolutivas para a reforma do sistema escolar alemão. Pelo contrário, suas pesquisas visavam a agudizar a crise de sentidos da escola pelo tensionamento dos ideais do projeto de escolarização com os seus resultados práticos, compreendendo a escola na sua relação dialética negativa com a sociedade, conforme já teorizado por Adorno (VILELA, 2009).

O procedimento do grupo de pesquisadores liderados por Gruschka está fundado em três pilares: (a) o conhecimento da crítica filosóficosociológica realizada por Adorno; (b) a compreensão das promessas iluministas de atingimento da autonomia pela educação (refletindo sobre a tríade Bildung, Erziehung e Didaktik - formação, educação e ensino) e (c) a hermenêutica objetiva aplicada em sala de aula para verificar a relação entre o que é - a realidade da educação revelada pela sala de aula, enquanto objeto materializado nos protocolos, e o que deveria ser - os referidos ideais iluministas que conduziriam o ser humano à autonomia (VILELA, 2009). Profundo conhecedor da obra de Adorno e contando com o apoio de Oevermann, Gruschka passou a aplicar a hermenêutica objetiva para análise do evento que, em sua compreensão, é capaz de materializar todos os ideais educativos: a aula (2014b).

Dos projetos de pesquisa de Gruschka que tiveram como base a referida metodologia, merece especial atenção o chamado de Pädagogische Rekonstruktion des Unterrichtens (Reconstrução pedagógica do ensinar), que produziu um inestimável banco de dados com protocolos de aulas registrados entre 2004 e 2013, os quais foram analisados e encontram-se disponibilizados online, e deram origem ao livro Unterrichten - eine pädagogische Theorie auf empirischer Basis ${ }^{13}$, de 2013. Seguindo rigorosamente o procedimento de Oevermann, as aulas do quinto ao oitavo ano, de diferentes disciplinas, foram gravadas em áudio e, posteriormente, transformadas em protocolo por uma equipe interdisciplinar de pesquisadores. Umas das principais riquezas da análise

${ }^{13}$ Ensinar - uma teoria educacional com base empírica, em nossa tradução. 
realizada é partir da interpretação do sentido de cada aula isoladamente para buscar as regularidades significativas que relacionam diversas escolas, com distintos projetos pedagógicos (VILELA, 2009). O relato do projeto de pesquisa coordenado por Rita Amélia Teixeira Vilela (2009), envolvendo a PUC-Minas e a Universidade de Frankfurt, aponta uma série de questões interessantes evidenciadas pelo rico material empírico produzido por Gruschka. Em suas conclusões, ela aponta que:

[h]á revelações preocupantes. A sala de aula tem se revelado como um ambiente empobrecido para o crescimento intelectual dos alunos. No lugar da discussão, do desafio da curiosidade, impera a rotina, o desestímulo para o crescimento pessoal. A socialização dos alunos nesse tipo de sala de aula não pode formar os sujeitos com autonomia de pensamento e ação presentes nos discursos que apontam serem essas as demandas sociais para a educação da contemporaneidade. Que tipo de educação tem sido, portanto, produzido dentro da sala de aula? Verificase, ainda, como a forma de discussão gerada pela aplicação da metodologia "Hermêutica Objetiva" não aponta conclusões, as evidências são tomadas para formular perguntas que se relacionam com a chamada crise da escola, perguntas que procuram esclarecer o que se passa na sala de aula e como situações da sala de aula são importantes para a compreensão dos problemas existentes. O conjunto das situações de sala de aula, acumuladas no processo de pesquisa, poderão compor um quadro analítico sobre o como a sala de aula pode explicar a escola de hoje. Essa é a finalidade das pesquisas (VILELA, 2009, p. 99).

Nesse sentido, para Gruschka a aula (micro) é um acontecimento tão rico de significados e elementos para a compreensão da situação da educação em seu aspecto geral (macro), na medida em que materializa, no tempo e no espaço, os ideais formativos em nível formal e ideal (legislação, currículo, plano político-pedagógico etc.) com as pressões de fato que o mercado exerce sobre a escola.

Da infinidade de elementos que as pesquisas coordenadas por Gruschka aportam para pensar a situação da educação escolar, são especialmente significativas aquelas constantes da obra Frieza burguesa e educação: a frieza como mal-estar moral da cultura burguesa na educação (2014a). Em referida obra, o educador alemão analisa, à luz da Teoria Crítica e a partir da base empírica produzida de acordo com a hermenêutica objetiva, uma das contradições centrais da relação entre educação e mercado: a formação da moralidade. A análise teórica realizada 
por Gruschka, fartamente amparada em protocolos produzidos com base na hermenêutica objetiva, tensiona as condições reais nas quais se desenvolve a educação escolar na contemporaneidade, cada vez mais determinada pelas regras do mercado, marcado pelo individualismo, concorrência etc., com os ideais contidos nos documentos orientadores. Gruschka (2014a) conclui que tal relação não apenas deixa de favorecer o desenvolvimento de um senso moral nos estudantes, como efetivamente impede que isso ocorra.

Por fim, é importante ressaltar que, no Brasil, existem projetos de aplicação da hermenêutica objetiva, dentre os quais destacam-se os relatos de Luiz Roberto Gomes (2017) e de Rita Amélia Teixeira Vilela (VILELA; NOACK-NÁPOLES, 2010; RORIZ; VILELA, 2016), havendo a expectativa de que seja disponibilizado na internet o banco de dados dos protocolos das pesquisas realizadas.

\section{Considerações finais}

De todo o argumentado, é possível afirmar que a hermenêutica objetiva é uma abordagem de pesquisa que mantém a sua atualidade e pertinência, especialmente em tempos de progressiva mercantilização da educação, tanto em nível internacional quanto no cenário brasileiro, com a malfadada reforma do ensino médio conduzida por interesses eminentemente vinculados com a operacionalização do ensino em função dos interesses do capital. Por sua vez, a atualidade de referida abordagem de pesquisa está fundada na atualidade das análises teóricas da Teoria Crítica. Contudo, a referida atualidade não está ancorada em formulações teóricas fixas, mas em um modo de compreender o mundo e produzir conhecimento. É exemplar nesse sentido, a seguinte citação, que evidencia a relação entre Adorno e as abordagens metodológicas em geral e, ao mesmo tempo, diz respeito a Oevermann e a Gruschka.

Em 2003, na sua fala de abertura do evento que organizou com Oevermann para discutir Adorno na atualidade, pela passagem do 100 aniversário do teórico, Gruschka saudou os convidados para o debate dizendo que esperava deles ouvir suas experiências de pesquisas e análises nos diferentes campos das ciências sociais e humanas ali representadas, sem que o pesquisador tivesse que citar Adorno. Com isso queria dizer, e ele mesmo explicou, que a forma de condução de trabalhos científicos fertilizados na Teoria Crítica fosse uma marca de identificação do processo 
de produção do conhecimento a ser comunicado nos debates. Em tom de brincadeira disse que não estava exigindo isso, mas que considerava possível. Para Gruschka, a forma de homenagear Adorno seria, portanto, a demonstração da fertilidade de sua teoria para a pesquisa social, esperava assim contribuições de pesquisas e estudos pautados na epistemologia de Adorno (VILELA, 2010, p. 1).

Nesse sentido, o próprio Adorno (2008, p. 178) advertiu que é necessário "desenvolver o método a partir do assunto" e que o "conhecimento não possui nenhum de seus objetos completamente" (ADORNO, 2009, p. 20). Assim sendo, é fundamental, aos pesquisadores do campo educacional, e das ciências humanas e sociais em geral, um consistente conhecimento teórico e metodológico, para implementar pesquisas robustas teoricamente, com bases empíricas ou não, de acordo com o objeto escolhido, pois "[a]sí como sin teoría no es posible comprobar nada, toda comprobación culmina en la teoría" (ADORNO, 2001, p. 51). Independentemente da abordagem metodológica escolhida pelo pesquisador, o que a Teoria Crítica exige de toda pesquisa é que ela seja capaz de produzir um conhecimento de resistência à crescente operacionalização do mundo em torno de interesses que se mostram cada vez mais particulares.

Por fim, o grande desafio para a utilização da hermenêutica objetiva nas pesquisas em Educação na atualidade parece guardar relação muito mais com as condições materiais para execução de referido método em um cenário de sucateamento das abordagens críticas do que as questões metodológica em si.

\section{Referências:}

ADORNO, Theodor W. Dialética Negativa. Rio de Janeiro: Jorge Zahar, 2009.

ADORNO, T.W. Experiências científicas nos Estados Unidos. In: Palavras e sinais: modelos críticos. Trad. Maria Helena Ruschel. Petrópolis: Vozes, 1995.

ADORNO, T.W. Introdução à sociologia. Tradução de Wolfgang Leo Maar. São Paulo: Editora UNESP, 2008.

ADORNO, T. W. Epistemología y ciencias sociales. Trad. Vicente Gómez. Madrid: Cátedra, 2001. 
ADORNO, Theodor W.; HORKHEIMER, Max. Dialética do Esclarecimento. Rio de Janeiro: J. Zahar, 1985 .

ANTUNES, Deborah. De Frankfurt à Califórnia: há continuidade nas pesquisas empíricas da Escola de Frankfurt entre 1929 e 1950? VI Seminário de PósGraduação em Filosofia da UFSCar, 2010. Disponível em: < http://www.ufscar.br/ semppgfil/wp-content/uploads/2012/05/DeborahChristina-Antunes-De-Frankfurt-à-Califórnia-há-continuidade-nas-pesquisasemp \% C3\%ADricas-da-Escola-de-Frankfurt-entre-1929-e-1950.pdf>. Acesso em abr. 2018.

ANTUNES, Deborah. Por um conhecimento sincero do mundo falso. Jundiaí: Paco, 2014.

DUARTE, Rodrigo. À procura de uma indução especulativa - filosofia e pesquisa empírica. In: Psicologia \& Sociedade, v. 13 (2), jul./dez. 2001, pp. 18-33. Disponível em: $<$ http://principo.org/associaco-brasileira-de-psicologia-social-abrapsopsicologia- .html?page $=4$ > . Acesso em 15 de abr. 2018.

FLECK, Amaro. O que é Teoria Crítica? In: Princípios Revista de Filosofia. Natal, v. 24, n. 44, Maio-Ago. 2017, p. 97-127. Disponível em: $<$ https://periodicos.ufrn.br/principios/article/download/12083/pdf $>$. Acesso em: abr. 2018.

GOMES, Luiz Roberto. Hermenêutica objetiva e pesquisa empírica em educação: a experiência com os estudos de sala de aula em Frankfurt am Main. In: Revista Eletrônica de Educação, v.11, n.2, p. 351-367, jun./ago., 2017.

GRUSCHKA, Andreas. Frieza burguesa e educação: a frieza como mal-estar moral da cultura burguesa na educação. Campinas: Autores Associados, 2014a.

GRUSCHKA, Andreas. Teoria crítica e pesquisa empírica em educação: a escola e a sala de aula. In: Constelaciones. Madri, n. 6, pp. 3-31, dezembro, 2014 b.

HORKHEIMER, Max. A presente situação da filosofia social e as tarefas de um instituto de pesquisas sociais. Praga: estudos marxistas. n. 7, 1999, p. 121-132.

JAY, Martin. La imaginación dialéctica. Madri: Taurus, 1989.

NOBRE, Marcos. A Teoria Crítica. Rio de Janeiro: Jorge Zahar Ed., 2014.

RORIZ, Edna Gomes; VILELA, Rita Amélia Teixeira. A Sala de Aula de Ciências: Uma Pesquisa Sobre as Práticas Curriculares em Uma Escola Pública de Belo Horizonte. In: Revista @rquivo Brasileiro de Educação, Belo Horizonte, v.4, n. 7, jan-abr, 2016. 
764 | Veritas | Porto Alegre, v. 63, n. 2, maio-ago. 2018, p. 744-764

SOUZA, Ricardo Timm de. Razões plurais - Itinerários da racionalidade ética no século XX. Porto Alegre: EDIPUCRS, 2004.

VILELA, Rita Amélia Teixeira. A análise sociológica "Hermenêutica Objetiva" - novas perspectivas na pesquisa qualitativa, 2011. Disponível em: <http://31reuniao.anped.org.br/1trabalho/gt14-4741--int.pdf>. Acesso em 15 abr. 2018.

VILELA, Rita Amélia Teixeira. A pesquisa empírica da sala de aula na perspectiva da Teoria Crítica aportes metodológicos da Hermenêutica Objetiva de Ulrich Oevermann, 2010. Disponível em: $<$ http://portal.pucminas.br/imagedb/mestrado doutorado/publicacoes/PUA AR Q ARQUI20120827111552.pdf > . Acesso em: 05 abr. de 2018.

VILELA, Rita Amélia Teixeira. A presença da Teoria Crítica no debate e na pesquisa educacional no Brasil e na Alemanha no período de 1995 à atualidade. Relatório de Pesquisa, CNPq 2006- 2008. PUC-Minas, 2009. Disponível em: <www.ich.ped/pucminas.br>. Acesso em: 05 abr. 2018.

VILELA, Rita Amélia Teixeira. Críticas e possibilidades da educação e da escola nacontemporaneidade: lições de Theodor Adorno para o currículo. Educação em Revista, Belo Horizonte, v. 45, p. 223-248. jun. 2007.

VILELA, Rita Amélia Teixeira; NOACK-NAPOLES, Juliane. "Hermenêutica Objetiva" e sua apropriação na pesquisa empírica na área da Educação. In: Linhas Críticas, Brasília, DF, v. 16, n. 31, p. 305-326, jul./dez. 2010.

WELLER, Wivian. Aportes hermenêuticos no desenvolvimento de metodologias qualitativas. In: Linhas Críticas, Brasília, DF, v. 16, n. 31, p. 287-304, jul./dez. 2010 .

WIGGERSHAUS, Rolf. A Escola de Frankfurt: história, desenvolvimento teórico, significação política. Tradução do alemão por Lilyane Deroche-Gurgel; tradução do francês por Vera de Azambuja Harvey; revisão técnica por Jorge Coelho Soares. Rio de Janeiro: DIFEl, 2002.

\section{Endereços Postal:}

PPG em Educação da PUCRS

Av. Ipiranga 6681, Porto Alegre - RS, Brasil

Data de recebimento: 25/05/2018

Data de aceite: 17/o9/2018 